\title{
Individual and mixture toxicity evaluation of three pharmaceuticals to the germination and growth of Lactuca sativa seeds
}

\author{
Diana Rede ${ }^{\text {a }}$, Lúcia H.M.L.M. Santos ${ }^{\text {b }}$, Sandra Ramos ${ }^{\text {c,de, }}$, Filipe Oliva-Teles ${ }^{\text {f,g }}$, Cristina Antão ${ }^{\text {h }}$, \\ Susana R. Sousa ${ }^{\mathrm{ci,j}, *}$, Cristina Delerue-Matos ${ }^{\mathrm{a}, \mathrm{c}}$ \\ a REQUIMTE/LAQV, Instituto Superior de Engenharia do Porto, Instituto Politécnico do Porto, Rua Dr. António Bernardino de Almeida, 431, 4200-072 Porto, Portugal \\ b ICRA - Catalan Institute for Water Research, Carrer Emili Grahit 101, 17003 Girona, Spain \\ c ISEP - Instituto Superior de Engenharia do Porto, Instituto Politécnico do Porto, Rua Dr. António Bernardino de Almeida, 431, 4200-072 Porto, Portugal \\ d CEAUL - Centro de Estatística e Aplicações da Universidade de Lisboa, Faculdade de Ciências, Universidade de Lisboa, Bloco C6 - Piso 4, Campo Grande, $1749-016$ Lisboa, Portugal \\ e LEMA, Instituto Superior de Engenharia do Porto, Instituto Politécnico do Porto, Rua Dr. António Bernardino de Almeida, 431, 4200-072 Porto, Portugal \\ ${ }^{\mathrm{f}}$ Departamento de Biologia, Faculdade de Ciências, Universidade do Porto, Rua do Campo Alegre, 4169 - 007 Porto, Portugal

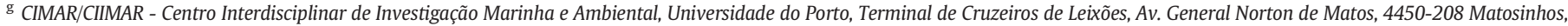 \\ Portugal \\ h Equilibrium, Laboratório de Controlo de Qualidade e de Processo, Lda., Praceta João Villaret, n. ${ }^{\circ}$ 183, 4460-337 Senhora da Hora, Portugal \\ i i3S - Instituto de Investigação e Inovação em Saúde, U. Porto, Rua Alfredo Allen, 208, 4200-135 Porto, Portugal \\ ${ }^{\mathrm{j}}$ INEB - Instituto de Engenharia Biomédica (INEB), Rua Alfredo Allen, 208, 4200-135 Porto, Portugal
}

\section{H I G H L I G H T S}

- Amoxicillin, ibuprofen and paracetamol acute effects on Lactuca sativa were tested.

- Germination and early plant growth were evaluated after a 5-day exposure.

- The exposure to single pharmaceuticals boosted the length of L. sativa.

- Mixtures of pharmaceuticals prevent the effects of isolated compounds.

\author{
Keywords: \\ Phytotoxicity \\ Lactuca sativa \\ Amoxicillin \\ Paracetamol \\ Ibuprofen \\ Mixtures
}

\section{A B S T R A C T}

This work aims to assess, individually and in mixtures, possible phytotoxic effects of three pharmaceuticals (paracetamol, ibuprofen and amoxicillin) on germination and early growth of Lactuca sativa seeds. Pharmaceuticals are an important group of emerging contaminants, whose presence has been described in several environmental compartments, including soils. However, knowledge on their possible impact in terrestrial organisms is still sparse and even more when mixtures are considered. Germination tests are important to evaluate the quality of soil and the toxic effects that contaminants can pose to plants.

The acute effects of individual pharmaceuticals as well as binary and ternary mixtures were assessed using different endpoints, namely: percentage of seed germination, root elongation, shoot and leaf length, after an exposure time of five days. Overall, in the exposure of $L$. sativa seeds to individual pharmaceuticals there are indications of acute toxicity in the early plant growth. However, this inhibitory effect tends to be cancelled in the acute exposure to mixtures. This study shows the importance of evaluating the toxicity of mixtures of pharmaceuticals, since they might have distinct toxic effects when compared to the single compounds, and also because, probably, it is the closest scenario to the reality that can be found in the environment. 


\section{Introduction}

The increasing global population and ever higher average life expectancies, cause pharmaceuticals to be continuously released into the environment, so they do not need to be persistent to jeopardize ecosystems (Santos et al., 2010; Arnold et al., 2013; Vasquez et al., 2014; Christou et al., 2019). Pharmaceuticals can be discharged into the environment through different sources, such as inappropriate disposal or via wastewater after excretion (Singh et al., 2018). As the removal of these substances in wastewater treatment plants (WWTPs) is not complete, pharmaceuticals and their metabolites can be released straight into the aquatic environment and ultimately they may reach drinking water (Petrie et al., 2015). In addition, either biosolids generated in WWTPs or manure produced by animals can be applied as fertilizers in agriculture, and reclaimed water can be used for crop irrigation. Moreover, pharmaceuticals may be part of the runoff from soils during rainfall reaching surface water or they can also infiltrate into groundwater (Edwards et al., 2009; Bártíková et al., 2016; Hurtado et al., 2016).

Trace concentrations of pharmaceuticals have been detected in a wide range of ecosystems, and show potential to bioaccumulate in organisms, which has raised concerns over the possible adverse effects from long-term exposure (Ruhí et al., 2016; de Solla et al., 2016; Moreno-González et al., 2016; Paíga et al., 2017; Christou et al., 2019). Most of the published data on ecotoxicology has focused on aquatic organisms (e.g. phytoplankton, marine bacteria, algae, crustaceans or fish) and only a few on soil inhabiting organisms (e.g. invertebrates, plants, soil bacteria and fungi). There are studies for phytoremediation purposes or in order to ascertain potential human exposure through trophic transfer (Carvalho et al., 2014). However, documented toxicity effects of pharmaceuticals in terrestrial plants are sparse (Hillis et al., 2011; Carvalho et al., 2014; Bártíková et al., 2016). As these emerging pollutants do not occur in the environment as isolated substances, studies on mixtures are important to investigate the potential for combined effects, such as antagonistic, synergistic or additive (Trombini et al., 2016).

Analgesics, non-steroidal anti-inflammatory drugs (NSAIDs) and antibiotics are among the most prescribed and consumed pharmaceuticals all over the world. Paracetamol (PCT), ibuprofen (IBU) and amoxicillin (AMX) are examples of pharmaceuticals representative of the aforementioned therapeutic classes. Their presence has been reported in different environmental compartments, namely wastewaters (Guillén et al., 2012; Gros et al., 2013; Santos et al., 2013), surface waters (Zuccato et al., 2010; Paíga et al., 2016), drinking water (Morasch et al., 2010; Carmona et al., 2014) and soils (Gibson et al., 2010; Gottschall et al., 2012; Vazquez-Roig et al., 2012; Li, 2014; Aznar et al., 2014). It was shown that these pharmaceuticals might have a potential toxic effect for non-target organisms, but it must be taken into account that the concentrations of exposure not always correspond to the ones found in environment (Pino et al., 2016). Paracetamol was classified as harmful to the copepod Tisbe battagliai (Trombini et al., 2016), and exhibited toxicity to a variety of other aquatic species such as: the unicellular algae Pseudokirchneriella subcapitata, the cyanobacterium Cylindrospermopsis raciborskii, the duckweed Lemna minor or the crustacean Daphnia magna (Nunes et al., 2014a). IBU was described as harmful to T. battagliai (Trombini et al., 2016) and to the crustacean Atyaephyra desmaresti (Nieto et al., 2016). It also caused a significant decrease in the reproduction and population growth rate of $D$. magna (Heckmann et al., 2007). Acute toxic effects have also been described for terrestrial organisms as the earthworm Eisenia fetida (Pino et al., 2015) and the crop plant L. sativa (Schmidt and Redshaw, 2015). On the other hand, AMX stimulated the photosynthesis activity and the production of microcystins of Microcystis aeruginosa (Liu et al., 2016). This pharmaceutical was also able to induce oxidative stress in the zebrafish (Dania rerio) (Oliveira et al., 2013) and seemed to affect the haemocyte parameters of the clam Ruditapes philippinarum and the mussel Mytilus galloprovincialis (Matozzo et al., 2016). AMX also showed toxicity to terrestrial organism, affecting the photosynthetic processes in wheat (Triticum aestivum) (Opri et al., 2013). Although the toxic effects of single pharmaceuticals have been described at different trophic levels, the current knowledge on the effects of their mixtures is still sparse, especially in terrestrial organisms (Vasquez et al., 2014).

In this study three widely consumed pharmaceuticals from different therapeutic groups (PCT, IBU and AMX) were selected to evaluate their possible phytotoxic effects on the germination, development and growth of Lactuca sativa seeds (lettuce). Based on direct contact, L. sativa was chosen, because it is a standard species recommended for ecotoxicological studies involving terrestrial plants due to their simplicity, low cost, and suitability to quickly react to the exposure to chemicals (OECD, 2006; D'Abrosca et al., 2008; Bragança et al., 2018). Single and mixture (binary and ternary) trials were conducted to assess the phytotoxic impact of individual pharmaceuticals and their mixtures in different endpoints, namely seed germination percentage and the length of each organ of the plant (root, shoot and leaf) after an exposure time of five days.

\section{Materials and methods}

\subsection{Test organisms, soil and chemicals}

Lettuce seeds (Lactuca sativa var. Buttercrunch; lot no. PTXT13413) were obtained from Alípio Dias \& Irmão (Porto, Portugal) and stored in the dark at $4{ }^{\circ} \mathrm{C}$. Acute toxicity tests were performed on a certified artificial sandy soil from MIBAL - Minas de Barqueiros S.A. (Apúlia, Portugal). This soil was slightly acid $(\mathrm{pH}=5)$ without organic matter content, a water holding capacity of $50 \%$, and a silica content of approximately $90 \%$, which $99.9 \%$ is sand and $0.1 \%$ is silt (Rede et al., 2016).

IBU (purity $\geq 99 \%$ ), AMX (potency $\geq 900 \mu \mathrm{g} \mathrm{mg}^{-1}$ ) and PCT (purity $\geq 98 \%$ ) were purchased from Sigma-Aldrich, Steinheim, Germany. Fresh stock solutions of pharmaceuticals were prepared in deionised water (resistivity $=15.2 \mathrm{M} \Omega \cdot \mathrm{cm}$ ) obtained from an Elix 3 Advanced system (Millipore; Molsheim; France). The solutions were renewed every 7 days and stored in the dark at $4{ }^{\circ} \mathrm{C}$ to avoid photodegradation.

\subsection{Experimental design}

Experimental procedure for acute ecotoxicity tests was set up according to Rede et al. (2016) (Rede et al., 2016), which was based on section A.8.6 "Lettuce seed germination (Lactuca sativa)" from EPA 600/3-88-029 (Greene et al., 1996) and EPS 1/RM/45 Report (Biological test method: test for measuring emergence and growth of terrestrial plants exposed to contaminants in soil) (Canada, 2005). Briefly, twenty seeds of L. sativa were placed onto $100 \mathrm{~g}$ of pre-dried $\left(104{ }^{\circ} \mathrm{C}, 24 \mathrm{~h}\right.$ ) sandy soil in polystyrene petri dishes $(\varnothing=140 \mathrm{~mm})$. Each seed was placed in a hole, covered with sand and $10 \mathrm{~mL}$ of deionised water/contaminant were added in the top of the soil using a Pasteur pipette. Petri dishes were sealed with parafilm and placed inside a germination 
chamber (Binder; KBWF 240; USA), equipped with day light fluorescent lamps, during $120 \mathrm{~h}$ at $24 \pm 2{ }^{\circ} \mathrm{C}$. The first $48 \mathrm{~h}$ were carried out in darkness, followed by $16: 8 \mathrm{~h}$ of light:dark cycles with a light intensity of $10,000 \mathrm{~lx}$.

After five days of exposure, plants were harvested, and root, shoot and leaf length was measured using a certified Digimatic Caliper (Mitutoyo; Absolute Series 500; USA). The germination percentage was calculated, and tests were considered valid if the germination of control test was $\geq 90 \%$ and the root length was up to $5 \mathrm{~mm}$.

The ecotoxicity of three pharmaceuticals (IBU, AMX and PCT) was evaluated using $L$. sativa seeds, considering either their individual phytotoxicity or the toxic effects of different mixture ratios. Each assay was made in triplicate and repeated three times, and the average germination percentage was calculated as well as the mean length of root, shoot and leaf.

\subsubsection{Artificial soil contamination with single pharmaceuticals}

Trials with each individual pharmaceutical were performed, covering a wide range of concentrations and their solubility in water. Assays with IBU were conducted in a concentration range between 0.01 and $100 \mathrm{ng} \mathrm{g}^{-1}\left(0.01,0.05,0.1,0.2,1,2,5,10,20,50\right.$, and $\left.100 \mathrm{ng} \mathrm{g}^{-1}\right)$. For AMX, it was used a concentration range between 0.01 and $10,000 \mathrm{ng} \mathrm{g}^{-1}(0.01,0.05,0.1,1,10,100,1000,5000$, and $10,000 \mathrm{ng} \mathrm{g}^{-1}$ ), and the ecotoxicity of PCT was studied in a concentration range between 0.001 and $10,000 \mathrm{ng} \mathrm{g}^{-1}(0.001,0.01,0.1,1,10$, $100,1000,5000$, and $\left.10,000 \mathrm{ng} \mathrm{g}^{-1}\right)$. The concentration of the stock solutions was confirmed by liquid chromatography. Rigorous dilutions were prepared in deionised water and $100 \mathrm{~g}$ of artificial soil was contaminated with $10 \mathrm{~mL}$ of diluted solution.

\subsubsection{Artificial soil contamination with mixtures of pharmaceuticals}

To study a more realistic scenario, L. sativa seeds were exposed to ten different mixtures of pharmaceuticals. For the 9 binary mixtures, the nominal concentration of each pharmaceutical was 10,50 or $90 \mathrm{ng} \mathrm{g}^{-1}$, and for the ternary mixture each pharmaceutical had a nominal concentration of $33.3 \mathrm{ng} \mathrm{g}^{-1}$ (Table S1, Supplementary material). In these experiments $100 \mathrm{~g}$ of soil were hydrated with $10 \mathrm{~mL}$ of each mixture, obtaining a final contamination of $100 \mathrm{ng}$ of pollutant per gram of artificial soil.

\subsection{Statistical analysis}

Tests were done triplicate, repeated in three distinct occasions and statistical analysis was performed using SPSS software, version 20.0 (SPSS Inc., Chicago, Illinois). Univariate descriptive statistics analysis was applied to the four studied endpoints, more specifically percentage of seed germination, root elongation, shoot length and leaf length. Data from acute ecotoxicity assays was analyzed through the application of a Kruskal-Wallis one-way ANOVA by rank test with Bonferroni correction. Subsequently a post-hoc comparison of mean rank of all pairs of groups was applied using Dunn test. A two-tailed $p_{\text {value }}<0.05$ was considered to indicate statistical significance.

\section{Results and discussion}

\subsection{Effect of individual pharmaceuticals in L. sativa seeds}

Fig. 1 shows the effect of the individual pharmaceuticals (PCT, IBU and AMX) in L. sativa seed germination and seedling growth after exposure to different concentrations for five days. In this study, no significant effects on seed germination were found for the three pharmaceuticals. This is in agreement with previous studies (Hillis et al., 2011; Pino et al., 2016), since the seed germination is a conservative process and the seed coat works as a protective barrier that protects the plant embryo from the negative impact of environmental contaminants like pharmaceuticals (An et al., 2009; Hillis et al., 2011; Vazquez-Roig et al., 2012). A small inhibition of the seed germination was described for wheat when exposed to pharmaceuticals (An et al., 2009).

The exposure of $L$. sativa seeds to PCT in a range of concentrations between 0.01 and $10,000 \mathrm{ng} \mathrm{g}^{-1}$ (equivalent to 0.1 to 100,000 $\mu \mathrm{g} \mathrm{L}{ }^{-1}$ ) did not cause statistically significant effects on percentage of seed germination, root elongation, shoot length and leaf length (Fig. 1AI-AIV), comparatively to the control. Pino et al. (2016) reported an $\mathrm{EC}_{50}$ of $2820 \mathrm{mg} \mathrm{L}^{-1}$ for the inhibition of root elongation of $L$. sativa after a five-day exposure to PCT (Pino et al., 2016), but Triticum aestivum (common wheat) was more affected by this pharmaceutical, exhibiting an $\mathrm{EC}_{50}$ of $668.8 \mathrm{mg} \mathrm{L}^{-1}$ after a fourteen-day exposure (An et al., 2009).

Within the range of IBU concentrations tested ( 0.01 to $100 \mathrm{ng} \mathrm{g}^{-1}$, equivalent to 0.1 to $1000 \mu \mathrm{g} \mathrm{L}{ }^{-1}$ ) no impact in the germination percentage and leaf length was observed. In fact, it was possible to see leaves in all the germinated seeds of lettuce after a five-day exposure, contrary to what was described by Schmidt and Redshaw (2015) who reported that only $20 \%$ of $L$. sativa seeds reached the cotyledon opening stage after a seven-day exposure period to IBU, at environmentally relevant concentrations (10 $\mathrm{g} \mathrm{L}^{-1}$ and $1 \mathrm{mg} \mathrm{L}^{-1}$ ) (Schmidt and Redshaw, 2015). Once more, these results were obtained for a longer exposure time than the one presented in EPA 600/3-88-029 (Greene et al., 1996). For the shoot length there were statistically significant differences between control and $0.05 \mathrm{ng} \mathrm{g}^{-1}(\mathrm{p}=0.017)$ and $0.1 \mathrm{ng} \mathrm{g}^{-1}(\mathrm{p}=0.004)$. In addition, statistically significant difference was also detected between $0.1 \mathrm{ng} \mathrm{g}^{-1}$ and $10 \mathrm{ng} \mathrm{g}^{-1}(\mathrm{p}=0.027)$, which represented an increment in the length of about $38 \%$. Concerning root elongation, roots became thinner and longer compared to the controls, but these differences were not statistically significant (Fig. 1BI-BIV). Schmidt and Redshaw (2015) observed an enhancement in L. sativa and $R$. sativus roots for a similar concentration of IBU $\left(1 \mathrm{mg} \mathrm{L}^{-1}\right.$ ) (Schmidt and Redshaw, 2015). However, for $250 \mathrm{mg} \mathrm{L}^{-1}$ of IBU Pino et al. (2016) described morphological changes in the radicles of L. sativa as they became yellow, with necrotic tips, underdeveloped hairs, and with thinner and longer roots than in controls (Pino et al., 2016). When the concentration of IBU increased to 500 or $1000 \mathrm{mg} \mathrm{L}^{-1}$, it was also observed necrotic tissue in the root tips, that for the highest concentration could extend to the radicle (Pino et al., 2016).

The exposure of $L$. sativa seeds to AMX in a concentration range between 0.01 and $10,000 \mathrm{ng} \mathrm{g}^{-1}$ (equivalent to 0.1 to $100,000 \mu \mathrm{g} \mathrm{L}^{-1}$ ) did not provoke statistically significant effects in germination percentage, root elongation, shoot and leaf length (Fig. 1CI-CIV). The slight change in the root elongation (from $-21 \%$ to $+25 \%$ ) comparatively to control agrees with the low toxicity described in the literature for L. sativa when exposed to a concentration range of AMX between 1 and 10,000 $\mu \mathrm{g} \mathrm{L}^{-1}$ (Hillis et al., 2011). Nevertheless, other species appear to be more sensitive to this pharmaceutical as is the case of Daucus carota which showed a significant decrease in the root and total length when exposed to AMX concentrations between 1 and $10,000 \mu \mathrm{g} \mathrm{L}^{-1}$ (Hillis et al., 2011). The root elongation of Medicago sativa was significantly stimulated when exposed to $1 \mu \mathrm{g} \mathrm{L}{ }^{-1}$ of AMX (Hillis et al., 2011). Moreover, concentrations of 0.5 and $1.5 \mathrm{mg} \mathrm{L}^{-1}$ of AMX seemed to reduce the capacity of light reactions of photosynthesis in T. aestivum, and consequently the resistance to stress conditions could be compromised (Opri et al., 2013).

No consistent differences or trends were observed in the concentration ranges of PCT, IBU and AMX tested, which allow the conclusion that if exposure occurs at environmentally relevant concentrations the threat to germination and development of $L$. sativa seeds is negligible. However as plants can uptake pharmaceuticals (by diffusion through cell walls and membranes), and accumulate them in their tissues, the presence of these pollutants in soil can pose a potential risk to the quality of agricultural products or even promote antibiotic resistance (Sabourin et al., 2012; Calderón-Preciado et al., 2013; Vasquez et al., 2014; Schroeder et al., 2015; Azanu et al., 2016; Christou et al., 2017b, 2019; Di Baccio et al., 2017). 
Al

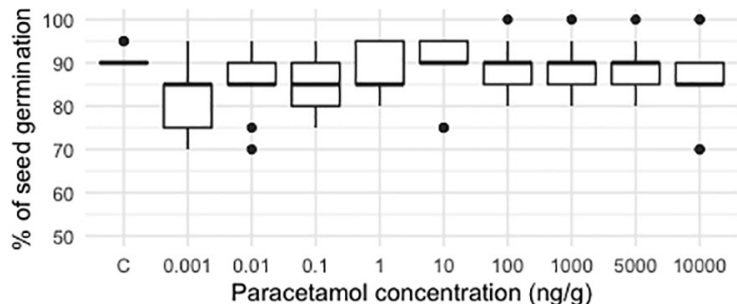

AIII

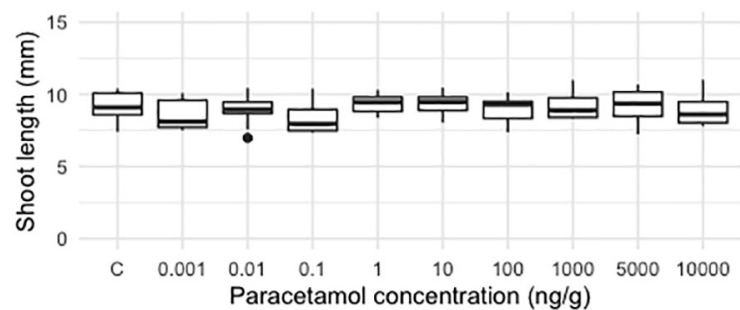

BI

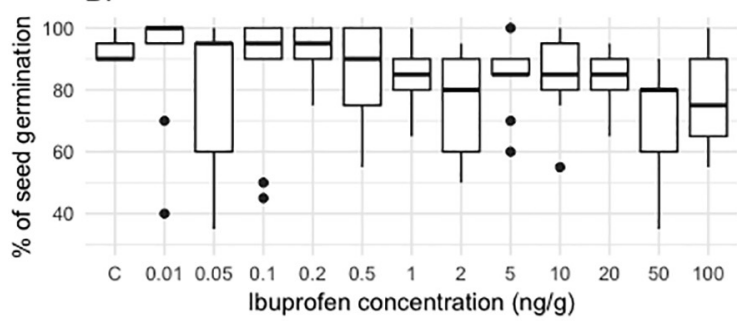

BIII

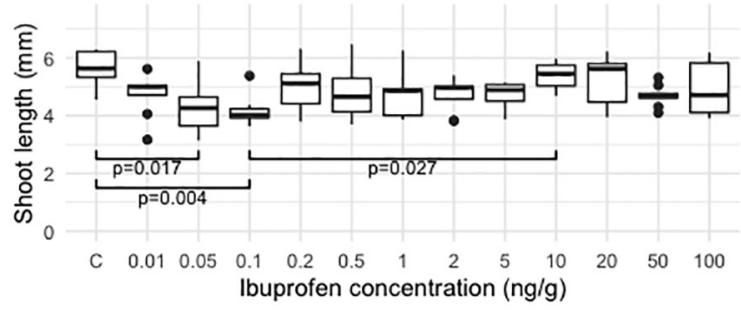

$\mathrm{Cl}$

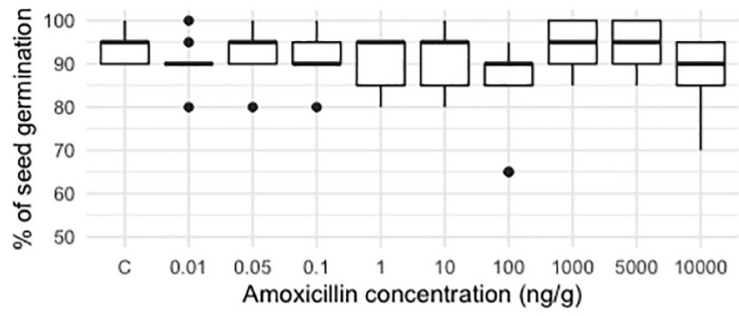

CIII

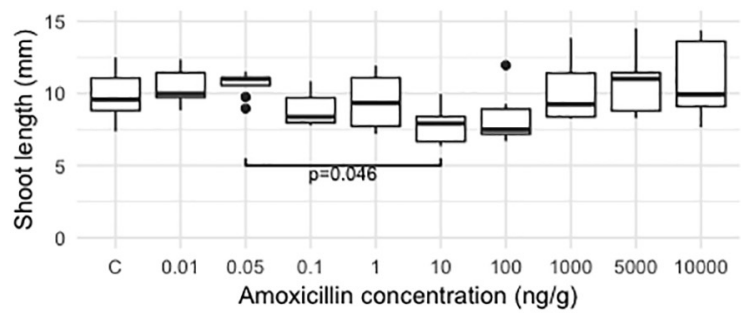

All

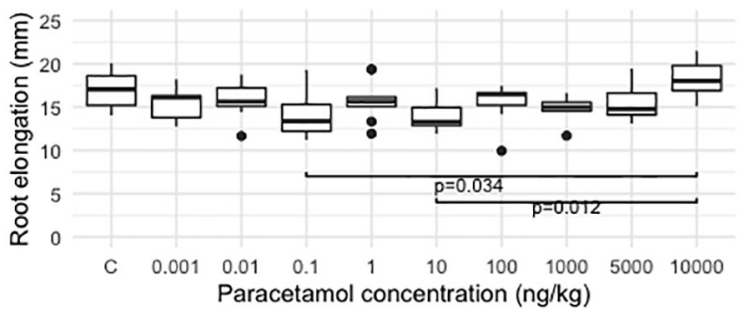

AIV

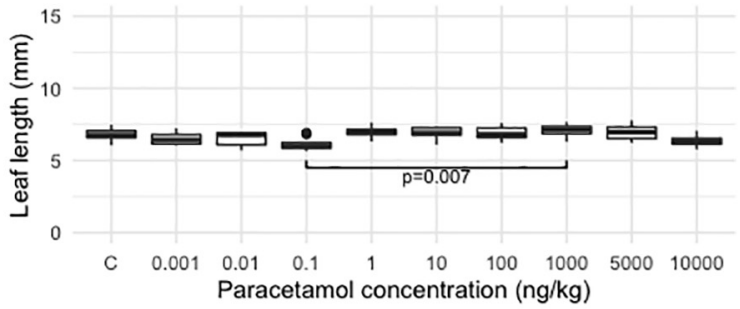

BII

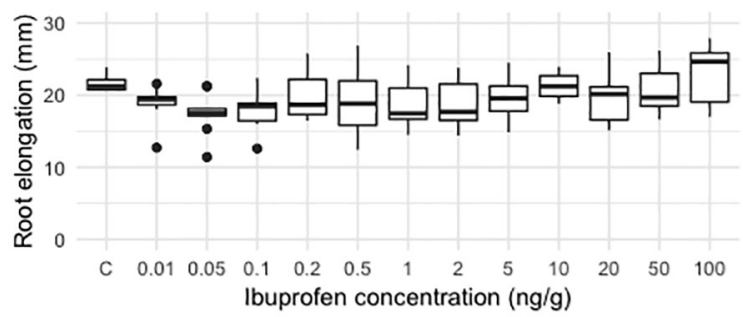

BIV

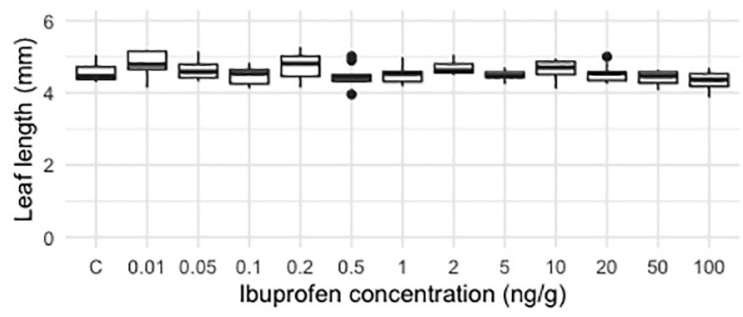

CII

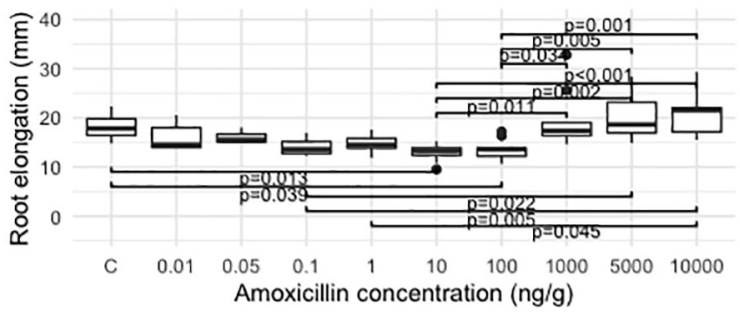

CIV

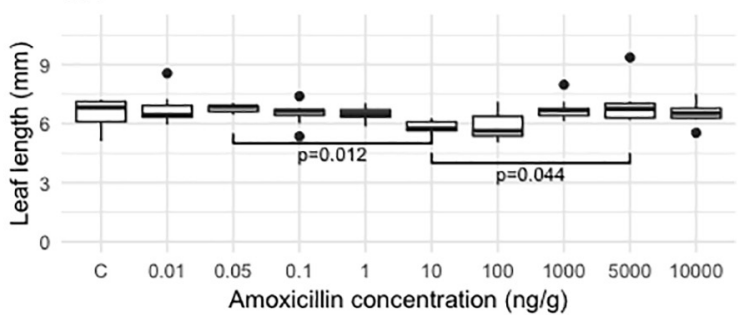

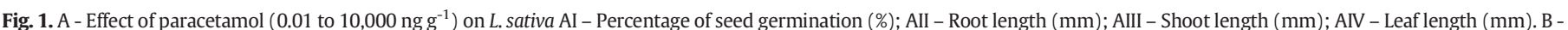

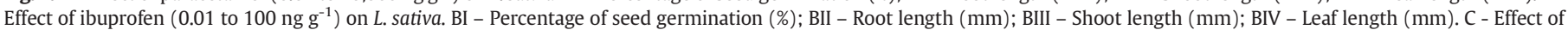

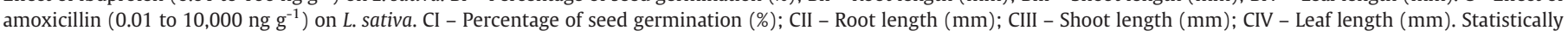
significant differences for a p value $<0.05 ; \square, \ldots$, ।, and $\bullet$, correspond to $25-75 \%$, median, non-outlier range, and outliers, respectively. 


\subsection{Effect of pharmaceuticals mixtures in L. sativa seeds}

The toxic effects of mixtures of PCT, IBU and AMX in the germination, and early growth of $L$. sativa seeds were also assessed. For that, a sum of concentrations of pharmaceuticals of $100 \mathrm{ng} \mathrm{g}^{-1}$ was considered in all tested mixtures, though different proportions of the pharmaceuticals were considered as an attempt to establish their possible impact in the observed phytotoxic effects. Therefore, several binary combinations of the three pharmaceuticals were made (see Table S1, Supplementary material), namely: for mixture I (MAI, MBI, MCI), a proportion of $10 \mathrm{ng} \mathrm{g}^{-1}$ of a pharmaceutical and $90 \mathrm{ng} \mathrm{g}^{-1}$ of the other; mixture II (MAII, MBII, MCII), both pharmaceuticals at the same concentration $\left(50 \mathrm{ng} \mathrm{g}^{-1}\right.$ ); and mixture III (MAIII, MBIII, MCIII), the opposite proportion of the pharmaceuticals considered in the mixture I. A ternary mixture (MD), combining PCT, IBU and AMX at the same concentration (33.3 $\mathrm{ng} \mathrm{g}^{-1}$ ) was also tested. In addition, isolated pharmaceuticals were also tested at a concentration of $100 \mathrm{ng} \mathrm{g}^{-1}$, which was considered the worst case scenario imposed by the solubility limit of the IBU in aqueous solutions.

When L. sativa was exposed to the mixtures of AMX and IBU the four endpoints (\% seed germination, root elongation, shoot length and leaf length) did not show statistically significant differences relative to the control ( $p>0.05$ ). Nevertheless, there were some statistically significant differences between individual pharmaceuticals and their combination. For the germination percentage, as it can be seen in Fig. 2-AI, there were statistically significant differences between IBU and the mixture MAIII ( $p=0.043$ ). Concerning root elongation statistically significant differences were observed relative to AMX, namely for the mixtures MAI ( $p$ $=0.012)$ and MAII $(\mathrm{p}=0.017)$. The effect was more pronounced for the mixture MAI (median $=24.49 \mathrm{~mm}$ ), which presented the highest amount of IBU (Fig. 2-AII). Moreover, it was noticed an increment in the shoot length of mixtures comparatively to the individual pharmaceuticals, that was significantly different from IBU (MAI: $\mathrm{p}=0.004$; MAII: $p=0.004$; MAIII: $p=0.002$ ). This effect was more pronounced for the mixture MAIII with an increment of about $174 \%$ and $73 \%$ to IBU and AMX, respectively (Fig. 2-AIII). For leaf length (Fig. 2-AIV) all mixtures of AMX and IBU showed an increase in the leaf length that was statistically significant different relative to IBU (MAI: $\mathrm{p}=0.045$; MAII: $\mathrm{p}=$ 0.0004; MAIII: $\mathrm{p}=0.004$ ).

The exposure of $L$. sativa to the mixtures of AMX and PCT did not induce statistically significant differences relative to the control $(p>0.05)$ in the four endpoints. Thought, there were statistically significant differences when mixtures were compared with individual pharmaceuticals. In the case of germination percentage, as it can be seen in Fig. 2-BI, mixture MBI was statistically significant different from AMX $(p=0.037)$. All mixtures showed an increment in the root elongation relatively to the individual pharmaceuticals (maximum increase of 41 and $85 \%$ compared to individual PCT and AMX, respectively). Moreover, mixtures $\mathrm{MBI}$ and MBII presented statistically significant differences compared to the individual exposure to AMX (MBI: $\mathrm{p}=0.023$; MBII: $\mathrm{p}=0.015$ ), mixture MBIII presented statistically significant differences compared to both individual pharmaceuticals (AMX: $\mathrm{p}<0.001$; PCT: $\mathrm{p}=0.009$ ) (Fig. 2-BII). Shoot length had the highest increase in the mixture MBIII (median $=12.18 \mathrm{~mm}$ ), which was statistically significant different from both individual pharmaceuticals (AMX: $\mathrm{p}=0.002$; PCT: $\mathrm{p}=$ 0.046 ). Furthermore, statistically significant differences in the shoot length was also observed in mixture MBI relative to AMX ( $p=0.033$ ) (Fig. 2-BIII). In relation to leaf length, mixtures showed an increase as well, being statistically significant different for MBII and MBIII relative to AMX ( $p=0.018$ and $p=0.009$, respectively) (Fig. 2-BIV).

Regarding the three mixtures of IBU and PCT no statistically significant differences were observed in any studied endpoint when compared to the control $(p>0.05)$. In the germination percentage (Fig. 2 $\mathrm{CI}$ ) there were statistically significant differences between IBU and the control ( $p=0.041$ ). Additionally, it can be said that the germination percentage increased in the mixtures (median $=95,0-97.5 \%$ ) in relation to IBU (median $=75.0 \%$ ). Root elongation tended to increase for all the mixtures (median $=19.96-25.56 \mathrm{~mm}$ ) relative to PCT (median $=16.49 \mathrm{~mm}$ ) (Fig. $2-\mathrm{CII}$ ). The effect was more pronounced when high proportions of IBU were present in the mixture as was the case of MCIII, that showed statistically significant differences from PCT $(p=0.001)$. As it can be seen in Fig. 2-CIII all the mixtures of IBU and PCT show an increment in the shoot length, that is significantly different relative to IBU (MCI: $p=0.0008$; MCII: $p=0.010$; MCIII: $p<0.001$ ). The same behaviour was observed for leaf length and once again all the mixtures presented statistically significant differences relatively to the individual exposure to IBU (MCI: $\mathrm{p}<0.001$; MCII: $\mathrm{p}=0.004$; MCIII: $\mathrm{p}=$ 0.0009) (Fig. 2-CIV).

The combination of the three pharmaceuticals did not affect endpoints when results were compared to control $(p>0.05)$, but there were statistically significant differences when compared with individual pharmaceuticals (Fig. 3). Root elongation of $L$. sativa increased compared to the individual pharmaceuticals, showing statistically significant differences relative to AMX $(p=0.003)$ which corresponded to an increment of about $120 \%$ (Fig. 3-B). The shoot length of the mixture presented an increase of $21 \%, 51 \%$ and $138 \%$ compared to PCT, AMX and IBU ( $<0.001$ ) (Fig. 3-C), respectively. Leaf length showed an identical tendency as shoot length, and statistically significant differences relative to IBU were noticed ( $p<0.001$ ), corresponding to an increment of about $86 \%$ (Fig. 3-D).

In general, for the same total concentration ( $\left.100 \mathrm{ng} \mathrm{g}^{-1}\right)$, an enhancement in the root elongation, shoot and leaf length of the lettuce exposed to the pharmaceutical mixtures was observed relative to the individual pharmaceuticals. The inhibitory effect on early growth detected on exposure to isolated pharmaceuticals tends to be cancelled in the mixtures, which might be due to interactions between compounds or even to the plant's own metabolism. It is known that the presence of isolated pharmaceuticals in the soil can induce oxidative stress in plants and then, their antioxidant defenses can be induced (Gómez-Oliván et al., 2014), leading to different responses (phytotoxic effects) depending on the pharmaceutical, its concentration and the sensitivity of the plant species (Carvalho et al., 2014; Marsoni et al., 2014; Minden et al., 2017). For instance, IBU acts by inhibiting cyclooxygenases, enzymes that are responsible for the catalysis of the prostaglandins synthesis. In higher plants, prostaglandins are involved in defense mechanisms (Cleuvers, 2004), therefore the exposure to this pharmaceutical might compromise the response of plants to the oxidative stress induced by pollutants present in soils. Furthermore, PCT induces oxidative stress in cells, leading to an increase in the reactive oxygen species (ROS) produced, which might damage the antioxidant defense system of the plant (An et al., 2009; Nunes et al., 2014b). PCT, IBU and AMX are widely consumed pharmaceuticals and have been detected in soils (Gottschall et al., 2012; Vazquez-Roig et al., 2012). It is not expected that the environmental concentrations of these pharmaceuticals could induce toxicity in the germination and development of lettuce seeds. Under real environmental conditions it is more likely to find mixtures of contaminants that continuously change composition and concentrations over time (Paíga et al., 2017; Christou et al., 2019). The bioaccumulation of contaminants in plant tissues depends on the type of soil, contaminants' physico-chemical properties and interactions, and also on the plant species (Christou et al., 2019). Toxic effects that long-time exposure to mixtures pose to non-target organisms are still poorly understood and should be considered to generate data (Cleuvers, 2003; Trombini et al., 2016; Pino et al., 2016; Christou et al., 2017a, 2019).

\section{Conclusions}

The individual and mixture phytotoxic effects of PCT, IBU and AMX in L. sativa seeds were assessed using four endpoints: percentage of seed germination, root elongation, shoot length and leaf length. Tests with isolated pharmaceuticals were conducted in a wide range of 

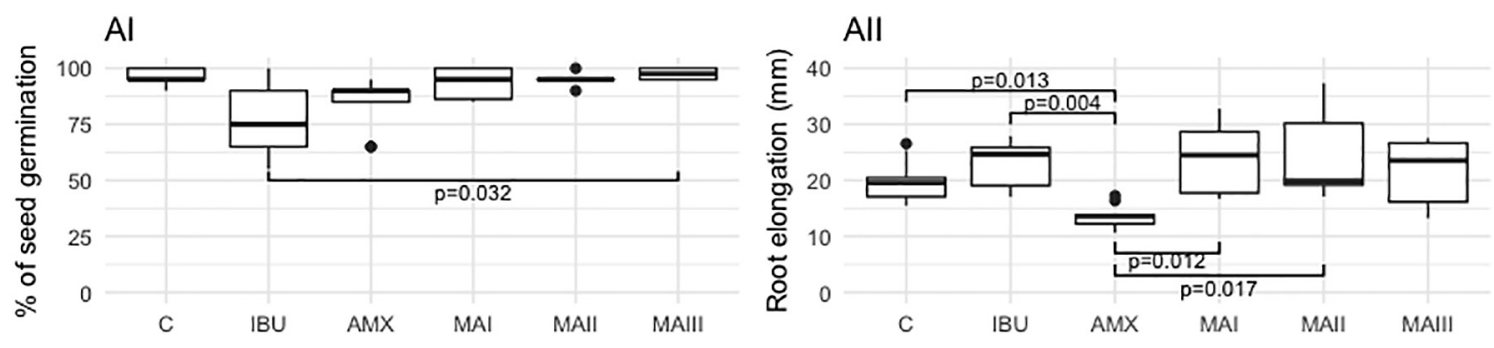

AIII
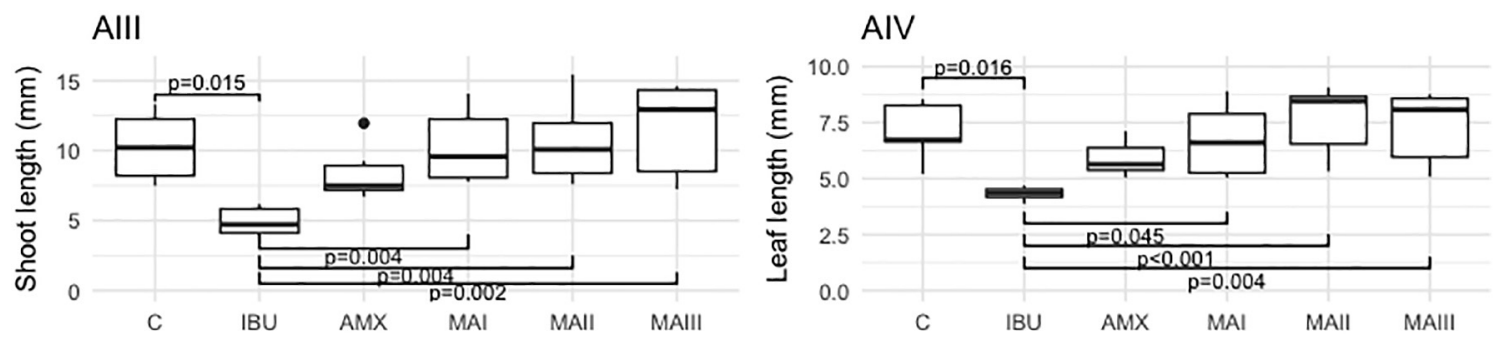

BI

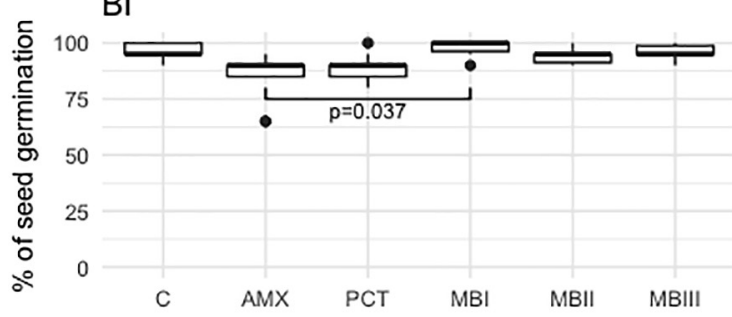

BII

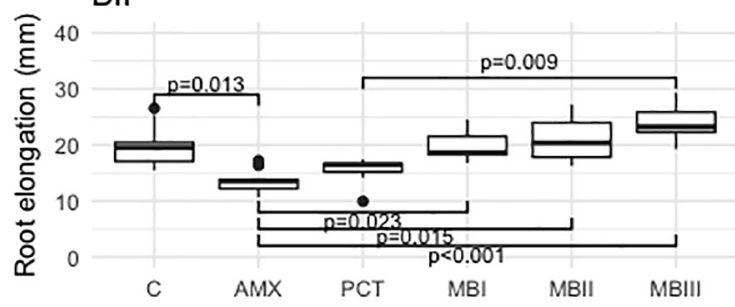

BIII

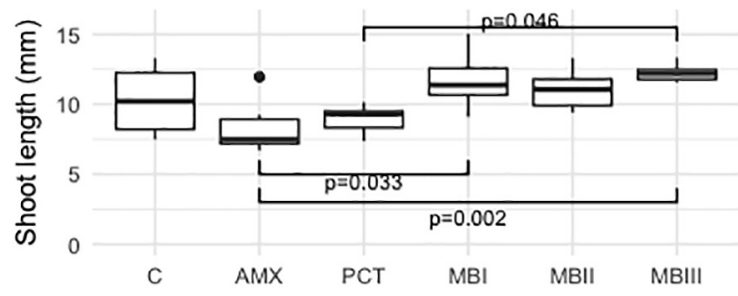

BIV

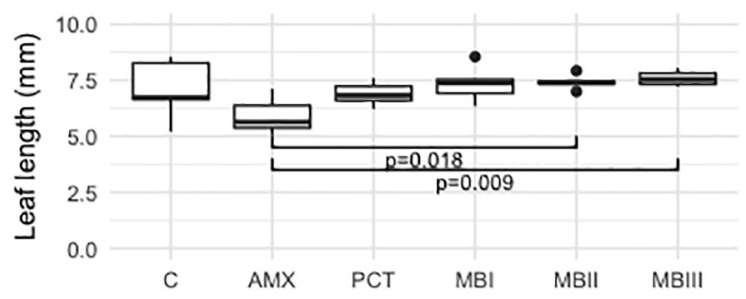

$\mathrm{Cl}$

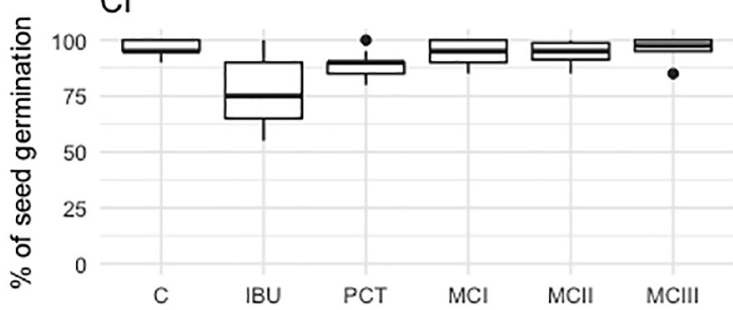

CII

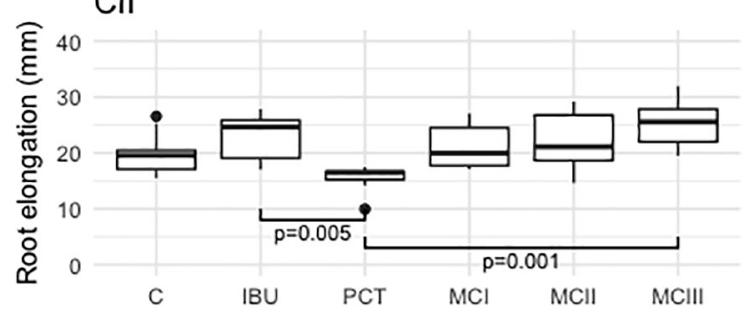

CIII

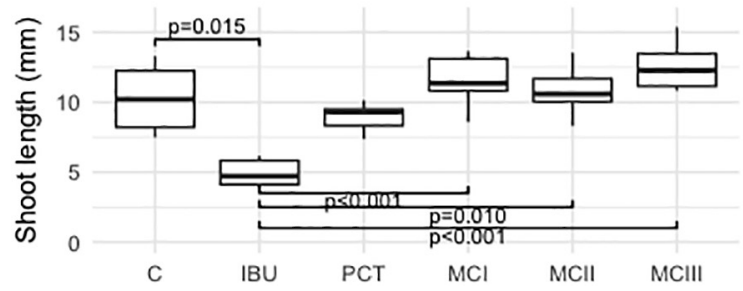

CIV

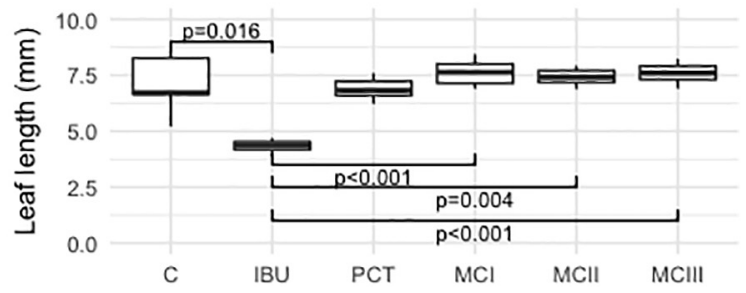

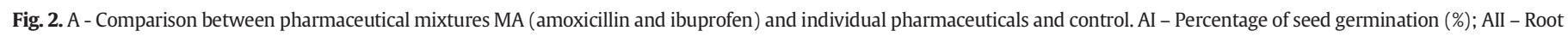

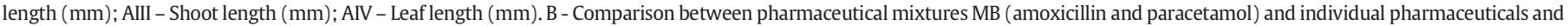

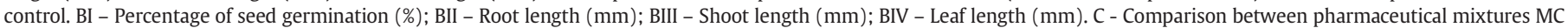

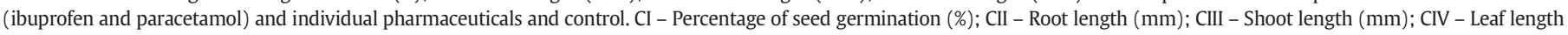
(mm). Statistically significant differences for a p value $<0.05 ; \square,-$, ।, and $\bullet$, correspond to $25-75 \%$, median, non-outlier range, and outliers, respectively. 
A

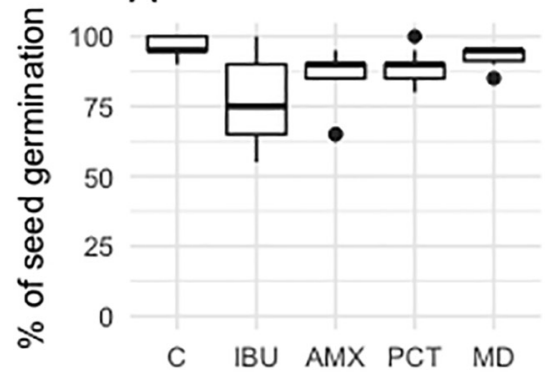

C

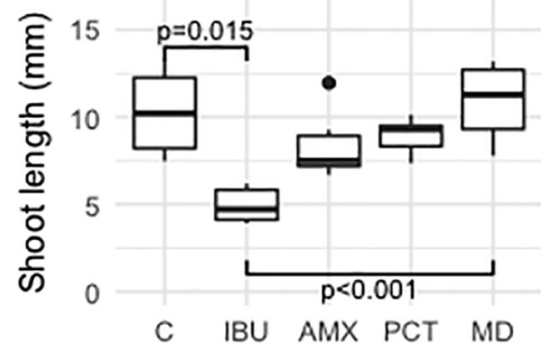

B

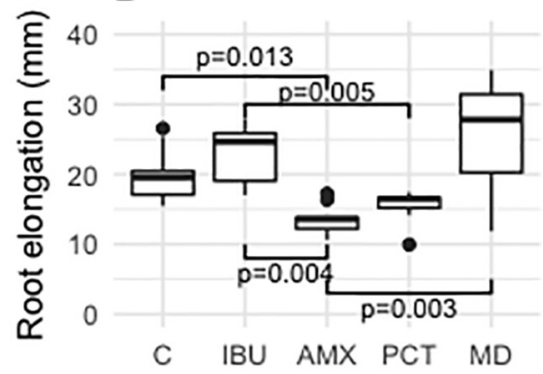

D

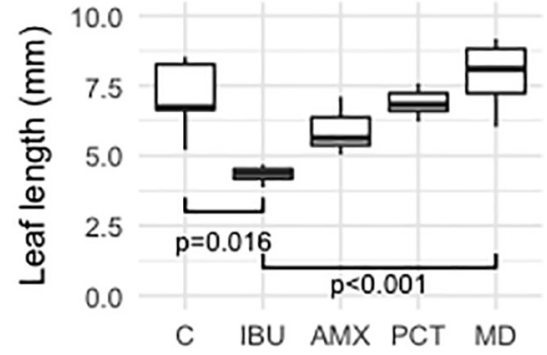

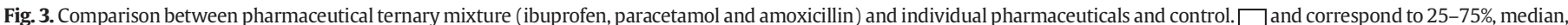

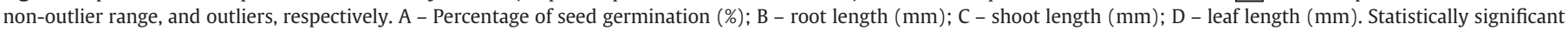
differences for a $\mathrm{p}$ value $<0.05$.

concentrations (PCT: $0.001-10,000 \mathrm{ng} \mathrm{g}^{-1}$; IBU: $0.01-100 \mathrm{ng} \mathrm{g}^{-1}$; AMX: $0.01-10,000 \mathrm{ng} \mathrm{g}^{-1}$ ). Ten mixtures with different proportions of the pharmaceuticals and a final concentration of $100 \mathrm{ng} \mathrm{g}^{-1}$ were tested.

For the tests with individual pharmaceuticals, the observed enhancement in $L$. sativa early seedling growth has no consistent statistical significance. When mixtures were evaluated, the inhibition in the early growth induced by isolated pharmaceuticals was not verified.

It is not expected that the environmental concentrations of PCT, IBU or AMX could induce toxicity in the early growth of lettuce seeds, though, in real environmental conditions, contaminants can be found as mixtures whose effects are not accurately determined by the analysis of individual compounds. To better understand the potential impact of pharmaceuticals and their mixtures on plants (either on their sustainability or on their productivity and food security), further phytotoxicological studies, mainly chronic tests, should be considered.

Supplementary data to this article can be found online at https://doi. org/10.1016/j.scitotenv.2019.03.432.

\section{Acknowledgments}

This work received financial support from the European Regional Development Fund (ERDF) through COMPETE - Operational Competitiveness Programme and national funds provided by FCT - Foundation for Science and Technology under the projects UID/QUI/50006/2013.

Lúcia H.M.L.M. Santos acknowledges the Juan de la Cierva program (FJCI-2014-22377).

\section{References}

An, J., Zhou, Q., Sun, F., Zhang, L., 2009. Ecotoxicological effects of paracetamol on seed germination and seedling development of wheat (Triticum aestivum L.). J. Hazard. Mater. 169, 751-757. https://doi.org/10.1016/j.jhazmat.2009.04.011.

Arnold, K.E., Boxall, A.B.A., Brown, A.R., et al., 2013. Assessing the exposure risk and impacts of pharmaceuticals in the environment on individuals and ecosystems. Biol. Lett. 9. https://doi.org/10.1098/rsbl.2013.0492.

Azanu, D., Mortey, C., Darko, G., et al., 2016. Uptake of antibiotics from irrigation water by plants. Chemosphere 157, 107-114. https://doi.org/10.1016/j. chemosphere.2016.05.035.
Aznar, R., Sánchez-Brunete, C., Albero, B., et al., 2014. Occurrence and analysis of selected pharmaceutical compounds in soil from Spanish agricultural fields. Environ. Sci. Pollut. Res. 21, 4772-4782. https://doi.org/10.1007/s11356-013-2438-7.

Bártíková, H., Podlipná, R., Skálová, L., 2016. Veterinary drugs in the environment and their toxicity to plants. Chemosphere 144, 2290-2301. https://doi.org/10.1016/j. chemosphere.2015.10.137.

Bragança, I., Lemos, P.C., Barros, P., et al., 2018. Phytotoxicity of pyrethroid pesticides and its metabolite towards Cucumis sativus. Sci. Total Environ. 619-620, 685-691. https://doi.org/10.1016/J.SCITOTENV.2017.11.164.

Calderón-Preciado, D., Matamoros, V., Savé, R., et al., 2013. Uptake of microcontaminants by crops irrigated with reclaimed water and groundwater under real field greenhouse conditions. Environ. Sci. Pollut. Res. 20, 3629-3638. https://doi.org/10.1007/ s11356-013-1509-0.

Canada E (2005) Biological Test Method: Test for Measuring Emergence and Growth of Terrestrial Plants Exposed to Contaminants in Soil. Report EPS 1/RM/45. Ontario, Canada.

Carmona, E., Andreu, V., Picó, Y., 2014. Occurrence of acidic pharmaceuticals and personal care products in Turia River Basin: from waste to drinking water. Sci. Total Environ. 484, 53-63. https://doi.org/10.1016/j.scitotenv.2014.02.085.

Carvalho, P.N., Basto, M.C.P. Almeida, C.M.R. Brix, H., 2014. A review of plantpharmaceutical interactions: from uptake and effects in crop plants to phytoremediation in constructed wetlands. Environ. Sci. Pollut. Res. 21, 11729-11763. https://doi.org/10.1007/s11356-014-2550-3.

Christou, A., Agüera, A., Bayona, J.M., et al., 2017a. The potential implications of reclaimed wastewater reuse for irrigation on the agricultural environment: the knowns and unknowns of the fate of antibiotics and antibiotic resistant bacteria and resistance genes - a review. Water Res. 123, 448-467. https://doi.org/10.1016/J.WATRES.2017.07.004.

Christou, A., Karaolia, P., Hapeshi, E., et al., 2017b. Long-term wastewater irrigation of vegetables in real agricultural systems: concentration of pharmaceuticals in soil, uptake and bioaccumulation in tomato fruits and human health risk assessment. Water Res. 109, 24-34. https://doi.org/10.1016/j.watres.2016.11.033.

Christou, A., Kyriacou, M.C., Georgiadou, E.C., et al., 2019. Uptake and bioaccumulation of three widely prescribed pharmaceutically active compounds in tomato fruits and mediated effects on fruit quality attributes. Sci. Total Environ. 647, 1169-1178. https:// doi.org/10.1016/j.scitotenv.2018.08.053.

Cleuvers, M., 2003. Aquatic ecotoxicity of pharmaceuticals including the assessment of combination effects. Toxicol. Lett. 142, 185-194. https://doi.org/10.1016/S03784274(03)00068-7.

Cleuvers, M., 2004. Mixture toxicity of the anti-inflammatory drugs diclofenac, ibuprofen, naproxen, and acetylsalicylic acid. Ecotoxicol. Environ. Saf. 59, 309-315. https://doi. org/10.1016/S0147-6513(03)00141-6.

D'Abrosca, B., Fiorentino, A., Izzo, A., et al., 2008. Phytotoxicity evaluation of five pharmaceutical pollutants detected in surface water on germination and growth of cultivated and spontaneous plants. J. Environ. Sci. Health A Tox. Hazard. Subst. Environ. Eng. 43 285-294. https://doi.org/10.1080/10934520701792803.

Di Baccio, D., Pietrini, F., Bertolotto, P., et al., 2017. Response of Lemna gibba L. to high and environmentally relevant concentrations of ibuprofen: removal, metabolism and morpho-physiological traits for biomonitoring of emerging contaminants. Sci. Tota Environ., 363-373 https://doi.org/10.1016/j.scitotenv.2016.12.191. 
Edwards, M., Topp, E., Metcalfe, C.D., et al., 2009. Pharmaceutical and personal care products in tile drainage following surface spreading and injection of dewatered municipal biosolids to an agricultural field. Sci. Total Environ. 407, 4220-4230. https://doi. org/10.1016/j.scitotenv.2009.02.028.

Gibson, R., Durán-Álvarez, J.C., Estrada, K.L., et al., 2010. Accumulation and leaching potential of some pharmaceuticals and potential endocrine disruptors in soils irrigated with wastewater in the Tula Valley, Mexico. Chemosphere 81, 1437-1445. https:// doi.org/10.1016/j.chemosphere.2010.09.006.

Gómez-Oliván, L.M., Neri-Cruz, N., Galar-Martínez, M., et al., 2014. Binary mixtures of diclofenac with paracetamol, ibuprofen, naproxen, and acetylsalicylic acid and these pharmaceuticals in isolated form induce oxidative stress on Hyalella azteca. Environ. Monit. Assess. 186, 7259-7271. https://doi.org/10.1007/s10661-014-3925-0.

Gottschall, N., Topp, E., Metcalfe, C., et al., 2012. Pharmaceutical and personal care products in groundwater, subsurface drainage, soil, and wheat grain, following a high single application of municipal biosolids to a field. Chemosphere 87, 194-203. https:// doi.org/10.1016/j.chemosphere.2011.12.018.

Greene, J.C., Bartels, C.L., Warren-Hicks, W.J., et al., 1996. Protocols for Short Term Toxicity Screening of Hazardous Waste Sites. USA, Chicago.

Gros, M., Rodríguez-Mozaz, S., Barceló, D., 2013. Rapid analysis of multiclass antibiotic residues and some of their metabolites in hospital, urban wastewater and river water by ultra-high-performance liquid chromatography coupled to quadrupolelinear ion trap tandem mass spectrometry. J. Chromatogr. A 1292, 173-188. https:// doi.org/10.1016/j.chroma.2012.12.072.

Guillén, D., Ginebreda, A., Farré, M., et al., 2012. Prioritization of chemicals in the aquatic environment based on risk assessment: analytical, modeling and regulatory perspective. Sci. Total Environ. 440, 236-252. https://doi.org/10.1016/j.scitotenv.2012.06.064.

Heckmann, L.-H., Callaghan, A., Hooper, H.L., et al., 2007. Chronic toxicity of ibuprofen to Daphnia magna: effects on life history traits and population dynamics. Toxicol. Lett. 172, 137-145. https://doi.org/10.1016/j.toxlet.2007.06.001.

Hillis, D.G., Fletcher, J., Solomon, K.R., Sibley, P.K., 2011. Effects of ten antibiotics on seed germination and root elongation in three plant species. Arch. Environ. Contam. Toxicol. 60, 220-232. https://doi.org/10.1007/s00244-010-9624-0.

Hurtado, C., Domínguez, C., Pérez-Babace, L., et al., 2016. Estimate of uptake and translocation of emerging organic contaminants from irrigation water concentration in lettuce grown under controlled conditions. J. Hazard. Mater. 305, 139-148. https://doi. org $/ 10.1016 / j$.jhazmat.2015.11.039.

Li, W.C., 2014. Occurrence, sources, and fate of pharmaceuticals in aquatic environment and soil. Environ. Pollut. 187, 193-201. https://doi.org/10.1016/j.envpol.2014.01.015

Liu, Y., Chen, S., Zhang, J., Gao, B., 2016. Growth, microcystin-production and proteomic responses of Microcystis aeruginosa under long-term exposure to amoxicillin. Water Res. 93, 141-152. https://doi.org/10.1016/j.watres.2016.01.060.

Marsoni, M., De Mattia, F., Labra, M., et al., 2014. Uptake and effects of a mixture of widely used therapeutic drugs in Eruca sativa L. and Zea mays L. plants. Ecotoxicol. Environ. Saf. 108, 52-57. https://doi.org/10.1016/j.ecoenv.2014.05.029.

Matozzo, V., Bertin, V., Battistara, M., et al., 2016. Does the antibiotic amoxicillin affect haemocyte parameters in non-target aquatic invertebrates? The clam Ruditapes philippinarum and the mussel Mytilus galloprovincialis as model organisms. Mar. Environ. Res. 119, 51-58. https://doi.org/10.1016/j.marenvres.2016.05.017.

Minden, V., Deloy, A., Volkert, A.M., et al., 2017. Antibiotics impact plant traits, even at small concentrations. AoB Plants 9. https://doi.org/10.1093/aobpla/plx010.

Morasch, B., Bonvin, F., Reiser, H., et al., 2010. Occurrence and fate of micropollutants in the Vidy Bay of Lake Geneva, Switzerland. Part II: micropollutant removal between wastewater and raw drinking water. Environ. Toxicol. Chem. 29, 1658-1668. https://doi.org/10.1002/etc.222.

Moreno-González, R., Rodríguez-Mozaz, S., Huerta, B., et al., 2016. Do pharmaceuticals bioaccumulate in marine molluscs and fish from a coastal lagoon? Environ. Res. 146, 282-298. https://doi.org/10.1016/j.envres.2016.01.001.

Nieto, E., Hampel, M., González-Ortegón, E., et al., 2016. Influence of temperature on toxicity of single pharmaceuticals and mixtures, in the crustacean A. desmarestii. J. Hazard. Mater. 313, 159-169. https://doi.org/10.1016/j.jhazmat.2016.03.061.

Nunes, B., Antunes, S.C., Santos, J., et al., 2014a. Toxic potential of paracetamol to freshwater organisms: a headache to environmental regulators? Ecotoxicol. Environ. Saf. 107, 178-185. https://doi.org/10.1016/j.ecoenv.2014.05.027.

Nunes, B., Pinto, G., Martins, L., et al., 2014b. Biochemical and standard toxic effects of acetaminophen on the macrophyte species Lemna minor and Lemna gibba. Environ. Sci. Pollut. Res. 21, 10815-10822. https://doi.org/10.1007/s11356-014-3059-5.

OECD, 2006. OECD Guidelines for the Testing of Chemicals, Updating Guideline 208 - Terrestrial Plants Test: Seedling Emergence and Seedling Growth Test.
Oliveira, R., McDonough, S., Ladewig, J.C.L., et al., 2013. Effects of oxytetracycline and amoxicillin on development and biomarkers activities of zebrafish (Danio rerio). Environ. Toxicol. Pharmacol. 36, 903-912. https://doi.org/10.1016/j.etap.2013.07.019.

Opri, O., Copaciu, F., Loredana Soran, M., et al., 2013. Influence of nine antibiotics on key secondary metabolites and physiological characteristics in Triticum aestivum: leaf volatiles as a promising new tool to assess toxicity. Ecotoxicol. Environ. Saf. 87, 70-79. https://doi.org/10.1016/j.ecoenv.2012.09.019.

Paíga, P., Santos, L.H.M.L.M., Ramos, S., et al., 2016. Presence of pharmaceuticals in the Lis river (Portugal): sources, fate and seasonal variation. Sci. Total Environ. 573, 164-177. https://doi.org/10.1016/j.scitotenv.2016.08.089.

Paíga, P., Santos, L.H.M.L.M., Delerue-Matos, C., 2017. Development of a multi-residue method for the determination of human and veterinary pharmaceuticals and some of their metabolites in aqueous environmental matrices by SPE-UHPLC-MS/MS. J. Pharm. Biomed. Anal. 135, 75-86. https://doi.org/10.1016/j.jpba.2016.12.013.

Petrie, B., Barden, R., Kasprzyk-Hordern, B., 2015. A review on emerging contaminants in wastewaters and the environment: current knowledge, understudied areas and recommendations for future monitoring. Water Res. 72, 3-27. https://doi.org/10.1016/j. watres.2014.08.053.

Pino, M.R., Val, J., Mainar, A.M., et al., 2015. Acute toxicological effects on the earthworm Eisenia fetida of 18 common pharmaceuticals in artificial soil. Sci. Total Environ. 518, 225-237. https://doi.org/10.1016/j.scitotenv.2015.02.080

Pino, M.R., Muñiz, S., Val, J., Navarro, E., 2016. Phytotoxicity of 15 common pharmaceuticals on the germination of Lactuca sativa and photosynthesis of Chlamydomonas reinhardtii. Environ. Sci. Pollut. Res. 23, 22530-22541. https://doi.org/10.1007/ s11356-016-7446-y.

Rede, D., Santos, L.H.M.L.M., Ramos, S., et al., 2016. Ecotoxicological impact of two soil remediation treatments in Lactuca sativa seeds. Chemosphere 159, 193-198. https:// doi.org/10.1016/j.chemosphere.2016.06.002.

Ruhí, A., Acuña, V., Barceló, D., et al., 2016. Bioaccumulation and trophic magnification of pharmaceuticals and endocrine disruptors in a Mediterranean river food web. Sci. Total Environ. 540, 250-259. https://doi.org/10.1016/j.scitotenv.2015.06.009.

Sabourin, L., Duenk, P., Bonte-Gelok, S., et al., 2012. Uptake of pharmaceuticals, hormones and parabens into vegetables grown in soil fertilized with municipal biosolids. Sci. Total Environ. 431, 233-236. https://doi.org/10.1016/j.scitotenv.2012.05.017.

Santos, L.H.M.L.M., Araújo, A.N., Fachini, A., et al., 2010. Ecotoxicological aspects related to the presence of pharmaceuticals in the aquatic environment. J. Hazard. Mater. 175, 45-95. https://doi.org/10.1016/J.JHAZMAT.2009.10.100.

Santos, L.H.M.L.M., Gros, M., Rodriguez-Mozaz, S., et al., 2013. Contribution of hospital effluents to the load of pharmaceuticals in urban wastewaters: identification of ecologically relevant pharmaceuticals. Sci. Total Environ. 461-462, 302-316. https://doi. org/10.1016/j.scitotenv.2013.04.077.

Schmidt, W., Redshaw, C.H., 2015. Evaluation of biological endpoints in crop plants after exposure to non-steroidal anti-inflammatory drugs (NSAIDs): implications for phytotoxicological assessment of novel contaminants. Ecotoxicol. Environ. Saf. 112, 212-222. https://doi.org/10.1016/j.ecoenv.2014.11.008.

Schroeder, L.M., Blackwell, B., Klein, D., Morse, A.N., 2015. Rate uptake of three common pharmaceuticals in celery, Apium Graveolens. Water Air Soil Pollut. 226, 1-20. https://doi.org/10.1007/s11270-014-2274-5.

Singh, V., Pandey, B., Suthar, S., 2018. Phytotoxicity of amoxicillin to the duckweed Spirodela polyrhiza: growth, oxidative stress, biochemical traits and antibiotic degradation. Chemosphere 201, 492-502. https://doi.org/10.1016/J.CHEMOSPHERE.2018.03.010.

de Solla, S.R., Gilroy, Ė.A.M., Klinck, J.S., et al., 2016. Bioaccumulation of pharmaceuticals and personal care products in the unionid mussel Lasmigona costata in a river receiving wastewater effluent. Chemosphere 146, 486-496. https://doi.org/10.1016/j. chemosphere.2015.12.022

Trombini, C., Hampel, M., Blasco, J., 2016. Evaluation of acute effects of four pharmaceuticals and their mixtures on the copepod Tisbe battagliai. Chemosphere 155, 319-328. https://doi.org/10.1016/j.chemosphere.2016.04.058.

Vasquez, M.I.I., Lambrianides, A., Schneider, M., et al., 2014. Environmental side effects of pharmaceutical cocktails: what we know and what we should know. J. Hazard. Mater. 279, 169-189. https://doi.org/10.1016/j.jhazmat.2014.06.069.

Vazquez-Roig, P., Andreu, V., Blasco, C., Picó, Y., 2012. Risk assessment on the presence of pharmaceuticals in sediments, soils and waters of the Pego-Oliva Marshlands (Valencia, eastern Spain). Sci. Total Environ. 440, 24-32. https://doi.org/10.1016/j. scitotenv.2012.08.036

Zuccato, E., Castiglioni, S., Bagnati, R., et al., 2010. Source, occurrence and fate of antibiotics in the Italian aquatic environment. J. Hazard. Mater. 179, 1042-1048. https://doi.org/ 10.1016/j.jhazmat.2010.03.110. 